\title{
A CULTURA CRISTÃ E A CULTURA PAGÃ NA PERSPECTIVA DE BASÍLIO MAGNO
}

\author{
Christian Culture and Pagan Culture \\ in Basil The Great's Perpective
}

Irineu Letenski ${ }^{1}$

\begin{abstract}
RESUMO: Estas reflexões têm como objetivo principal mostrar a possibilidade de um diálogo entre a cultura cristã e a cultura pagã na perspectiva de Basílio Magno, ou de Cesareia. Com efeito, três tendências marcaram a relação "sabedoria cristã" e "sabedoria pagã" nos primeiros séculos do pensamento cristão: uma tendência que vê uma quase equivalência entre estas duas áreas do saber (Justino Mártir), uma segunda tendência que estabelece um fosso intransponível entre ambas as esferas (Tertuliano) e, finalmente, uma tendência intermediária ou completar que liga uma à outra. É esta última que caracteriza o pensamento e os escritos de Basílio Magno. Todavia, devem-se também levar em conta os paradoxos e as ambiguidades que permeiam os textos do próprio Basílio. É o que este estudo tenta também explorar a partir da obra: Discurso aos jovens.
\end{abstract}

PALAVRAS-CHAVE: Basílio Magno; Cultura cristã; Cultura pagã; Discurso aos jovens; Paradoxos.

ABSTRACT: These reflections aim at showing the possibility of a dialog between Christian culture and pagan culture from Basil the Great's or Basil of Caesarea's point of view. Indeed, three tendencies marked the relationship between "Cristian wisdom" and "pagan wisdom" throughout the first centuries of the Christian thought: a tendency that sees an almost equivalence between both areas (Justin Martyr), another tendency that digs an insurmountable gap between the one and the other (Tertullian) and, finally, an intermediate or complementary tendency, which links both spheres of knowledge. It is the latter that characterizes the thought and writings of Basil the Great. Nonetheless, one must also consider the paradoxes and ambiguities that permeate Basil's own texts. This is what this study also intends to explore based on the writing: Address to Young Men.

KEYWORDS: Basil the Great; Christian culture; Pagan culture; Address to Young Men; Paradoxes.

\footnotetext{
${ }^{1}$ Doutor em filosofia pela Pontifícia Universidade Católica do Paraná (PUCPR), leciona filosofia na Faculdade São Basílio Magno (FASBAM) e na Faculdade de Tecnologia de Curitiba (FATEC-PR). E-mail: irineule@gmail.com
} 
Os inícios do pensamento cristão foram marcados não somente pelas controvérsias cristológicas e trinitárias que acarretaram os grandes concílios ecumênicos - Niceia (325), Constantinopla (381), Éfeso (431) e Calcedônia (451) -, mas também, mormente durante os quatro primeiros séculos, pelas relações entre a cultura cristã e a cultura pagão, também chamadas "sabedoria cristã" e "sabedoria pagã". No que tange a estas relações, Basílio Magno, ou Basílio de Cesareia (329/330-379), se situa naquilo que poderíamos denominar uma posição intermediária, ou complementar, pois para ele não existe nem uma simples equivalência entre a cultura cristã e a cultura pagã nem tampouco uma antinomia separando-as de maneira insuperável e irremediável. Efetivamente, conforme elucida Rogério Miranda de Almeida, a tradição filosófico-teológica ocidental se caracteriza fundamentalmente por três grandes tendências. A primeira é representada principalmente por Justino Mártir (c. 100-165), que vê uma quase equivalência entre a "sabedoria cristã" e a "sabedoria pagã", na medida em que ambas estavam à procura do Logos e, portanto, da Verdade. A segunda tem em Tertuliano (c. 155-c. 222) o seu mais veemente paladino, que apontava para um abismo intransponível entre fé e razão. Esta mesma tendência se prolongará, depois de Tertuliano, através dos teólogos e pensadores: Pedro Damião (1007-1072), Lutero (1483-1546) e, nos tempos modernos, Pascal (16231662), Kierkegaard (1813-1855) e Karl Barth (1886-1968). Temos finalmente a terceira tendência, na qual se incluem Clemente de Alexandria, os três Padres Capadócios (Basílio Magno, Gregório de Nissa e Gregório Nazianzeno), Agostinho de Hipona e, já na Idade Média, Anselmo de Aosta e Tomás de Aquino. ${ }^{2} \mathrm{Na}$ Idade Contemporânea e, mais precisamente, no século XX, sobressaem os nomes dos teólogos: Paul Tillich, Karl Rahner e Wolfhart Pannenberg.

Basílio Magno teve o privilégio de ter nascido no seio de uma família culta. De seu próprio pai recebeu as primeiras lições relativas às ciências clássicas e por intermédio de sua avó Macrina, discípula de Gregório Taumaturgo, hauriu os fundamentos da teologia alexandrina, notadamente aquela de Orígenes. Após ter frequentado a escola de retórica em Cesareia da Capadócia, onde se encontrou pela primeira vez com Gregório Nazianzeno, foi estudar retórica junto a Libânio em Constantinopla (c. 346-350) e, em seguida, em Atenas, onde recebeu lições dos célebres retores Himério e Proerésio e se encontrou mais uma vez com Gregório Nazianzeno. Foi também em Atenas que Basílio conheceu o Imperador Juliano. Após seu retorno à pátria (c. 356), dedicou-se ao ensino

\footnotetext{
${ }^{2}$ Cf. ALMEIDA, Rogério Miranda de. Agostinho de Hipona e as ambivalências do seu filosofar. In Revista Veritas, v. 57, n. 2, maio/agosto 2012, pp. 195-196.
} 
da retórica, abandonando-o logo em seguida para consagrar-se inteiramente à vida cristã e à ascese. Em 370, Basílio se tornou bispo de Cesareia, onde desenvolveu uma intensa atividade como pastor, teólogo e escritor.

Dentre os seus escritos, destacam-se obras de caráter exegético, dogmático, pedagógico e espiritual: Hexaemeron (Nove homilias sobre a obra dos seis dias); Contra Eunômio; Sobre o Espírito Santo; As regras monásticas e o Discurso aos jovens, também significantemente intitulado: Sobre a maneira de tirar proveito das letras pagãs. Dados, porém, os limites formais deste estudo, eu me aterei à obra, Discurso aos jovens, para, a partir dela, não somente mostrar a possibilidade de um diálogo entre a cultura cristã e a cultura pagã, mas também os aspectos paradoxais que este escrito encerra.

\section{Discurso aos jovens: duas culturas que se confrontam e se completam}

Para melhor entendermos esta obra, Discurso aos jovens, convém primeiramente transportarmo-nos para a época e a situação cultural, filosófica e religiosa em que viveu o próprio Basílio. Ora, de acordo com Rogério Miranda de Almeida:

A questão que caracterizou tanto a literatura apologética grega quanto aquela de expressão latina - meados do século II-início do século IV - foi a de elucidar, aprofundar e resolver a tensão oriunda do encontro e do embate entre, de um lado, a "sabedoria cristã" - cujas raízes mergulhavam na tradição judaica e, portanto, numa religião monoteísta centrada na revelação, na Lei, na voz, nas categorias de povo e de história - e, de outro, a "sabedoria pagã", cujas referências principais eram o politeísmo, a razão, o mito, a categoria de pólis, o conceito de logos e, consequentemente, a primazia da palavra enquanto expressão da continuidade racional do discurso. ${ }^{3}$

Com relação à questão da compatibilidade entre a "sabedoria cristã" e a "sabedoria pagã”, Justino Mártir faz certas declarações que podem parecer desconcertantes aos ouvidos daqueles que são pouco familiares com as doutrinas da participação e das razões seminais. Com efeito, diz o teólogo na Primeira Apologia:

Nós recebemos o ensinamento de que Cristo é o primogênito de Deus e indicamos antes que ele é o Verbo, do qual todo o gênero humano participou. Portanto, aqueles que viveram conforme o Verbo são cristãos, quando foram considerados ateus, como sucedeu entre os gregos com Sócrates, Heráclito e outros semelhantes. ${ }^{4}$

No Diálogo com Trifão, Justino se mostrará ainda mais explícito, ao asseverar: "De fato, a filosofia é o maior e o mais precioso bem diante de Deus, para o qual somente ela

\footnotetext{
3 ALMEIDA, Rogério Miranda de. "Filosofia cristã": Reflexões em torno de uma polêmica. In Espiritualidade, saúde e cultura: A teologia nas fronteiras. Curitiba: Juruá, 2016, p. 16.

${ }^{4}$ JUSTINO DE ROMA. I e II Apologias; Diálogo com Trifão. São Paulo: Paulus, 1995. I Apologia, 46, pp. 61-62. Itálicos meus.
} 
nos conduz e nos associa." Ao empregar o termo "filosofia", Justino o faz no sentido amplo que possui o conceito de sabedoria, inclusive, e principalmente, a sabedoria cristã. Ela pode também equivaler à palavra teologia, que Justino evita utilizar em virtude do contexto mitológico em que nasceu este termo. Por isso ele prefere servir-se da palavra "filosofia", com a qual parece sentir-se mais à vontade para afirmar: "Na verdade, santos são aqueles que consagram à filosofia a própria inteligência."

Diametralmente em oposição a esta visão se colocará Tertuliano ao prevenir seus leitores contra todo e qualquer tipo de compromisso com a filosofia, ou a razão. Neste sentido, ficaram célebres as interrogações e invectivas que ele lançara no sétimo capítulo de seu tratado Prescrição contra os heréticos: "O que têm, pois, em comum Atenas e Jerusalém? A Academia e a Igreja? Os heréticos e os cristãos? Se possuímos a fé, nada mais desejamos crer, pois começamos por crer que, para além da fé, nada mais existe que nos possa forçar a crer."

Ora, na época em que viveu Basílio Magno, século IV, a questão do encontro e do embate entre a "sabedoria cristã" e a "sabedoria "pagã", a "cultura cristã" e a "cultura pagã", era ainda uma questão premente. Foi, pois, neste contexto e, mais precisamente, entre os anos 370 e 375, que ele redigiu o Discurso aos jovens, muito provavelmente destinado a adolescentes e, talvez, a crianças que frequentavam a sua escola. Nesses pupilos a tradição costumava ver os parentes (sobrinhos e primos) do próprio Basílio, mas hoje este círculo foi estendido para os jovens em geral. É de se notar, conforme eu avancei no final da introdução, o outro título que se atribui ao Discurso aos jovens: Sobre a maneira de tirar proveito das letras pagãs. Isto quer dizer que Basílio não opõe resistência à chamada cultura ou sabedoria pagã, mas, pelo contrário, ele incentiva seus pupilos a haurirem tudo aquilo de bom e de proveitoso que esta cultura possa oferecer. Em outros termos - e conquanto Basílio acentue a superioridade da "sabedoria cristã" vis$\grave{a}$-vis da "sabedoria pagã" - ele considera em primeiro lugar os pontos em comum, relativos à verdade, que atravessam e, literalmente, permeiam essas duas esferas do saber: a cristã e a pagã.

E, de fato, nos capítulos que compõem o Discurso aos jovens, sobressai a elaboração retórica como uma constante referência aos conteúdos da cultura clássica, mas, ao mesmo tempo, é também dada ênfase à vida ascética e aos aspectos a ela relacionados. Melhor

\footnotetext{
${ }^{5}$ Ibid., Diálogo com Trifão, 2, p. 111.

${ }^{6}$ Ibid.

${ }^{7}$ TERTUlianO. Contro gli eretici. Roma: Città Nuova, 2002, VII, 9-10, p. 39.
} 
ainda: dificilmente se poderia separar, no método fundamental de Basílio, a retórica e a filosofia, porquanto ambas estão intrinsicamente arraigadas numa tradição que remonta bem além do pensamento cristão. Como observa o estudioso George L. Kustas, a retórica e a filosofia se influenciavam mutuamente, e dialeticamente, na antiguidade na medida em que a retórica não somente servia como um instrumento de persuasão, mas também ajudava a formular, disseminar e transformar as ideias provindas de tradições filosóficas que, por assim dizer, já começavam a cristalizar-se e, portanto, a perder seu frescor e sua novidade iniciais. Isto se revela ainda mais verdadeiro, sublinha o autor, na elevada cultura retórica do século IV. Daí a inevitável conclusão de Kustas: “O que Basílio recebe da filosofia ou de outra área do conhecimento passa primeiramente através do filtro retórico e é visto por ele, como deve ser visto por nós, em termos retóricos". ${ }^{8}$

Do ponto de vista formal, o Discurso aos jovens se compõe de dez capítulos, divididos, segundo Oskar Ring, em duas partes principais. Na primeira parte, que vai do Capítulo II ao Capítulo VI, Basílio analisa os escritos da literatura profana ou "externa", cujo conhecimento, de acordo com suas próprias palavras, é útil para a vida espiritual. $\mathrm{Na}$ segunda parte, que abrange os Capítulos VII-X,7, o autor ressalta os louváveis comportamentos e exemplos encontrados na cultura e na vida dos pagãos, cuja utilidade prática não se deve de modo algum negligenciar. Basílio conclui a obra (Capítulo X, 89) vinculando suas reflexões finais com o proêmio e exortando os jovens a seguirem as orientações, tanto no presente quanto no futuro, que ele acabara de lhes apresentar neste pequeno escrito. ${ }^{9}$

Ora, o que mais sobressai neste tratado é, justamente, a intenção pedagógica de Basílio, que se volta para os jovens estudantes e, indiretamente, para as pessoas desejosas de cultura a fim de lhes propor conselhos úteis e sugestões sobre o modo de adquirir conhecimentos nas obras da literatura pagã e, assim, progredir na vida do espírito. Tratase, portanto, de uma obra de caráter pedagógico e ao mesmo tempo ético e espiritual, na medida em que ela encerra uma proposta de ascese cristã. Na verdade, não é de admirar o fato de ter Basílio adotado um método centrado na retórica clássica grega, porquanto as instâncias pedagógicas do ensino cristão tinham como pano de fundo a educação clássicopagã, onde predominavam, conforme eu avancei mais acima, a dialética e a retórica. De

\footnotetext{
${ }^{8}$ KUSTAS, GEORGE L. Saint Basil and the Rhetorical Tradition, p. 230. In Basil of Caesarea: Christian, Humanist, Ascetic. A sixteen-Hundredth Anniversary Symposium. Paul Jonathan Fedwick (editor). Toronto: Pontifical Institute of Mediaeval Studies, 1981.

${ }^{9}$ Cf. NALDINI, Mario. Apud Basilio di Cesarea. Discorso ai giovani. Bologna: EDB, 1998, p. 21.
} 
resto, a dinâmica do ensino se baseava também na leitura assídua e no exercício mnemônico que se fazia sobre os clássicos gregos. Assim, segundo Mario Naldini, é neste âmbito e tendo em conta os valores educativos próprios da paideia grega que se exprime o Discurso aos jovens. O próprio Basílio - acentua o erudito italiano - revela neste escrito, mais do que em qualquer outro, o equilíbrio e a elegância peculiares a um espírito clássico. ${ }^{10}$

Convém, porém, observar que, ao dizer que Basílio se situa numa tendência intermediária e complementar vis-à-vis da cultura cristã e da cultura pagã, não significa afirmar que ele esteja isento de toda ambiguidade e de todo paradoxo. Pelo contrário, o próprio título - Sobre a maneira de tirar proveito das letras pagãs - sugere que não se trata de aceitar sem reservas tudo o que provém da cultura grega antiga. Antes, deve-se fazer uma triagem, uma seleção. Mas o paradoxo de Basílio consiste justamente nisto: ao defender a superioridade da cultura cristã, ele vê simultaneamente a necessidade de se dialogar e, por conseguinte, de se enriquecer com a cultura pagã. Em outros termos, ele não considera a cultura cristã e a cultura pagã como irredutivelmente antitéticas uma com relação à outra, mas, antes, como dois âmbitos em que os valores de um e de outro se excluem e ao mesmo tempo se incluem mutuamente. Trata-se daquela dinâmica que Rogério Miranda de Almeida designa pelas expressões: "o paradoxo do entre-dois", ou o "paradoxo de uma exclusão interna".

\section{Ambiguidades e paradoxos}

Efetivamente, já no Primeiro Capítulo do Discurso aos jovens, deparamo-nos com uma certa ambiguidade de Basílio no que tange à “cultura pagã” e à liberdade com a qual dela se pode utilizar. Pois o teólogo admoesta aos jovens: "É justamente este conselho que eu pretendo dar-vos: que não deveis prontamente seguir os escritos dos homens mais ilustres da antiguidade para onde eles vos quiserem levar". ${ }^{11}$ Logo em seguida, portanto, ele amplia a sua advertência: "Mas acolhendo tudo aquilo que eles possuem de bom, sabei também o que é necessário desconsiderar". ${ }^{12}$ Assistimos, pois, a uma dupla dinâmica neste confronto com a "cultura pagã": por mais que Basílio tenha sido educado nesta cultura e dela tenha haurido os valores, ele não deixa de prevenir e acautelar todos aqueles

\footnotetext{
${ }^{10}$ Cf. Basilio di Cesarea. Discorso ai giovani, op. cit., p. 10.

${ }^{11}$ Ibid., I, 6 .

${ }^{12}$ Ibid.
} 
que dela se servirem a fim de não tomarem de empréstimo a primeira ideia ou o primeiro escrito que ela lhes apresentar.

No capítulo seguinte, encontramos um Basílio que, sob mais de um aspecto, nos lembra Clemente de Alexandria, que fora igualmente influenciado pela cultura clássica grega e, como mais tarde o fará o próprio Basílio, também defendia a necessidade de se acolher tudo de bom que os pagãos têm a oferecer. De resto, tanto em Clemente de Alexandria quanto em Basílio é clara a influência de Platão e do neoplatonismo, na medida em que os escritos destes teólogos - e o Discurso em particular - enfatizam uma valorização da vida espiritual e, inversamente, uma depreciação de tudo aquilo que é terreno, mundano, sensível e material. ${ }^{13}$ Note-se também que o Apóstolo Paulo é, implícita ou explicitamente, um interlocutor privilegiado de Basílio, inclusive neste Capítulo II, 7. Curiosamente, o próprio Basílio retoma, neste mesmo capítulo, uma ideia semelhante àquela de Clemente ao afirmar que as Escrituras se apresentam como uma propedêutica, ou uma preparação, para o conhecimento pleno da verdade revelada em Cristo e, consequentemente, para a salvação de todos aqueles que se abrem para esta revelação. Declara, pois, o teólogo:

Àquela vida (a vida futura) certamente nos conduzem as Santas Escrituras, adestrando-nos mediante os mistérios. Mas até que, por razão de idade, não se conseguir compreender o significado profundo desses mistérios, nós nos exercitamos com o olhar da alma sobre outros livros, não totalmente diferentes destes. Agimos como que olhando sombras e nos vendo em espelhos, imitando aqueles que realizam exercícios militares. Estes, pela prática adquirida nos exercícios das mãos e do salto, tiram depois vantagem desse adestramento nas batalhas. ${ }^{14}$

Com estas ricas e belas metáforas - que nos conduzem imediatamente à alegoria da caverna - Basílio confronta, em termos platônicos, este mundo das sombras ou da sensibilidade com o mundo das essências inteligíveis e, em termos paulinos, esta vida terrena com a vida futura. A "cultura pagã" se apresenta, pois, como uma propedêutica ou uma educação no caminho para aquela vida que somente as Escrituras podem plenamente revelar. Curiosamente, Basílio emprega aqui a mesma metáfora de que se utilizara Platão no Livro IV da República, no contexto da análise das "virtudes cardeais" e, mais particularmente, da coragem. Mas em que consiste esta metáfora? Trata-se da

\footnotetext{
${ }^{13}$ A questão da influência do platonismo e, mais especificamente, do neoplatonismo sobre Basílio Magno se encontra analisada no estudo de John M. Rist, intitulado: Basil's "Neoplatonism". Its Background and Nature. In Basil of Caesarea: Christian, Humanist, Ascetic. A sixteen-Hundredth Anniversary Symposium, op. cit. No que concerne às ligações de Basílio com os pré-socráticos, Platão e Aristóteles, há um minucioso e erudito estudo de Leo V. Jacks, intitulado: St. Basil and Greek Literature. Washington D.C.: Catholic University of America, 1922.

${ }^{14}$ Basílio de Cesareia. Discorso ai giovani, op. cit., II, 7.
} 
figura do tintureiro que, segundo Platão, ao se prepar para tingir a lã de púrpura, não se serve da primeira lã que encontra. Mas, ao cotejar as diversas cores de lã, ele escolhe aquela que mais se adapte ao fim que ele tem em vista, isto é, a branca. No entanto, ele deve ainda trabalhá-la, através de um longo tratamento, para que ela adquira ao máximo o brilho da cor que nela ele quer aplicar. Somente depois deste meticuloso processo de triagem e preparação é que ele a mergulha na tintura e o resultado que daí se segue é a indelebilidade da própria tintura, de sorte que a lavagem feita com ou sem lixívia ou dissolventes não lhe subtrai a cor aplicada. Quando, porém, a lã é tingida precipitadamente, ou sem a preparação adequada, ela se torna, com a lavagem, desbotada ou desprovida de toda beleza. Com esta metáfora, Platão ilustra a educação adequada que deve ter, na pólis, a classe dos guerreiros ou guardiães. Para protegê-la de todo perigo interno ou de qualquer ameaça externa, os guardiães deverão adquirir, por analogia, a mais bela tintura possível destinada às leis. E, assim fazendo, eles se tornarão imunes àqueles terríveis dissolventes que, segundo Platão, são o prazer, a dor, o medo e o desejo. Pois é a força e a coragem que constantemente salvaguardam a reta e legítima opinião no que diz respeito às coisas que se devem temer. Consequentemente, e também por analogia, a coragem é uma virtude que deve igualmente ser preparada, trabalhada e exercitada para que o seu brilho permaneça inextinguível enquanto virtude. ${ }^{15}$

Se agora voltarmos ao Discurso, veremos que não é por acaso que, antes de empregar a metáfora do tintureiro, Basílio se refere ao combate para o qual a alma deve estar preparada para adquirir a sua salvação ou a "vida futura que supera esta vida terrena". Curioso também é constatar - e é aqui que se repete o caráter paradoxal de sua posição de paladino da doutrina cristã - a admoestação segundo a qual: "Devemos tornar familiares para nós os poetas, os historiadores, os retores e todos aqueles dos quais se possa extrair alguma utilidade para o cuidado da nossa alma”. ${ }^{16}$ Basílio se revela, pois, paradoxal na medida em que ele não hesita em sublinhar a superioridade da cultura e da sabedoria cristãs e, ao mesmo tempo, em fazer apelo para que os jovens se alimentem da cultura clássica pagã. É, portanto, neste contexto que ele introduz a metáfora do tintureiro da qual já se havia servido Platão na República. Todavia, o que ele irá enfatizar através desta figura é a questão do bem e da revelação dos mistérios que encerram as Escrituras e a doutrina cristã. Assim, pondera o teólogo, como os tingidores que antes preparam cuidadosamente um tecido apto a receber a tintura para neles aplicar a cor desejada, seja

${ }^{15}$ Cf. PLATÃO. Republic. Cambridge/London: Harvard University Press, 1978, 429d - 430b.

${ }^{16}$ Basilio di Cesarea. Discorso ai giovani, op. cit., II, 8. Itálicos meus. 
esta a púrpura ou de qualquer outra espécie, assim também nós, se quisermos que o bem permaneça indelével em nosso espírito, devemos exercitar-nos "nos estudos profanos" para podermos compreender os mistérios destas sacras doutrinas. Donde a sua conclusão: "E uma vez habituados a olhar, por assim dizer, o sol na água, lançaremos o olhar na própria luz". ${ }^{17}$

Segundo Mario Naldini, o Capítulo II, sucintamente analisado nestas reflexões, forma, com o Capítulo IV, uma seção definida em torno do binômio "graça - vaidade" e "utilidade" e "não utilidade" da cultura e dos escritos pagãos. Conforme eu acabei de mostrar, o Capítulo II manifesta, antes de tudo, uma atitude positiva quanto à valorização dos autores clássicos para a obtenção de uma sapiência superior. Do ponto de vista formal, ele se divide em duas partes: a primeira (seções 1-6) se ocupa do escopo transcendente da existência; a segunda (seções 7-10), que lança mão das metáforas da preparação militar e da técnica dos tintureiros, vê nas Escrituras a única via capaz de conduzir, de maneira segura, final e definitiva, àquela meta, que é a salvação. ${ }^{18}$

Ainda segundo Naldini, que se baseia nas análises de J. Cazeaux, o Capítulo III representa um papel de mediação entre o Capítulo II e o Capítulo IV. Isto quer dizer que aquele capítulo, literalmente, se inter-põe como uma espécie de charneira entre, de um lado, a utilidade da cultura pagã como propedêutica para o perfeito conhecimento de Deus através das Escrituras e, de outro, a distinção e diferenciação entre as duas tradições, ou culturas: a pagã e a cristã. No que diz respeito ao primeiro aspecto, Basílio começa por lançar este desafio: se existe alguma afinidade recíproca entre estas duas doutrinas - a pagã e a cristã - o conhecimento de ambas não poderá senão ser útil; se, porém, não existir nenhuma afinidade entre elas, o fato de colocá-las em confronto, para daí reconhecer as diferenças, ajudar-nos-á não pouco a conformarmo-nos com a melhor. Todavia, insiste o teólogo: com que poderemos comparar as duas doutrinas para delas fazermos uma imagem adequada? É neste ponto que ele faz uso de outra metáfora, desta vez, a metáfora da planta. Mas em que consiste a virtude peculiar a uma planta? Ela reside, segundo Basílio, no fato de cobrir-se de frutos da estação e, com as suas folhas que farfalham ao vento, formar um vistoso ornamento. É assim também, completa o teólogo, que acontece com a alma: o seu fruto por excelência é a verdade. Mas é justamente aqui que se encontra o paradoxo ou a ambiguidade fundamental de Basílio, pois ele ajunta: "Não é de forma

\footnotetext{
${ }^{17}$ Ibid., II, 9 - 10 .

${ }^{18}$ Cf. NALDINI, Mario. Apud Basilio di Cesarea. Discorso ai giovani, op. cit., pp. 144-145.
} 
alguma inoportuno que a alma se revista de sapiencia profana como as folhas que oferecem abrigo ao fruto e propiciam uma vista agradável". ${ }^{19}$

Lendo estas últimas declarações de Basílio, não podemos senão quedar surpresos se as compararmos com uma de suas missivas, onde ele reproduz, quase literalmente, aquela depreciação que lançara Paulo Apóstolo contra a "sabedoria do mundo". Com efeito, assevera o Apóstolo: "No entanto, é realmente de sabedoria que falamos entre os perfeitos, sabedoria que não é deste mundo nem dos príncipes deste mundo, votados à destruição. Ensinamos a sabedoria de Deus, misteriosa e oculta, que Deus, antes dos séculos, de antemão destinou para a nossa glória" (1Cor 2, 6-7). ${ }^{20}$ Ora, a confissão que nos confia Basílio na sua missiva não somente ecoa as palavras do Apóstolo Paulo, mas também contrasta patentemente com o encômio que, até o momento, vínhamos lendo no Discurso a respeito da cultura pagã. Assim, declara Basílio:

Dispendi muito tempo na vaidade e desperdicei quase toda a minha juventude em vão labor, no qual sofri e adquiri a sabedoria tornada em loucura por Deus. Pois, outrora, como um homem despertado de um sono profundo, eu voltei os meus olhos para a maravilhosa luz da verdade do Evangelho e percebi a inutilidade da sabedoria dos príncipes deste mundo, que em nada resulta. ${ }^{21}$

Isto se torna ainda mais paradoxal se pensarmos que, no Capítulo III do Discurso, Basílio afirma que os escritores do Antigo Testamento teriam sido instruídos por uma cultura extra bíblica. Moisés, por exemplo, teria aprendido a contemplar o Ser a partir das ciências egípcias e, melhor ainda, o profeta Daniel teria sido instruído em Babilônia pela ciência dos caldeus. ${ }^{22}$ Este mesmo Capítulo III se apresenta, conforme já avancei, sob a forma de uma ligação entre o Capítulo II e o Capítulo IV, na medida em que nele se desdobram as duas modalidades do saber: de um lado, a utilidade da cultura pagã como propedêutica para o perfeito conhecimento de Deus e, de outro, as diferenças entre a tradição pagã e a tradição cristã. No Capítulo IV, Basílio mais uma vez procede a um duplo movimento, mas, à diferença do Capítulo I, ele primeiramente enfatiza a utilidade que tem para a alma o conhecimento das ciências profanas; em seguida, ele põe em guarda os jovens sobre os cuidados que devem ter para saberem discernir e, portanto, utilizar estas ciências. Começando pelos poetas, ele pondera que, em se tratando de escritos de toda espécie de argumento, não se deve dar crédito a todos indistintamente, mas somente àqueles que apresentam fatos ou ditos de homens excelentes. Donde a sua exortação:

\footnotetext{
${ }^{19}$ Basilio di Cesarea. Discorso ai giovani, op. cit., III, 1-2. Itálicos meus.

${ }^{20}$ In A Bíblia de Jerusalém. São Paulo: Paulus, 1995.

${ }^{21}$ BASIL, Saint. Letters, volume II (186-368). In The Fathers of the Church. Washington, D.C.: The Catholic University Press, 2008, Letter 223, 2. Itálicos meus.

${ }^{22}$ Cf. Basilio di Cesarea. Discorso ai giovani, op. cit., III, 3.
} 
"Deve-se acolhê-los voluntariamente, segui-los com espírito de emulação e fazer todo o possível para imitá-los". ${ }^{23}$ Surpreendentemente, Basílio evoca neste contexto a figura de Ulisses, que teria tapado com as mãos os ouvidos para não se deixar seduzir pelo canto das sereias. Contudo, mais enfático ainda se revela o teólogo ao recomendar que se deve evitar o politeísmo e, mais precisamente, os poetas que trataram ou discorreram sobre os mitos, isto é, os deuses pagãos.

É ainda no Capítulo IV que Basílio emprega a célebre metáfora das abelhas que, na verdade, remonta a uma longa tradição: Píndaro, Isócrates, Virgílio, Sêneca, Plutarco e aqueles autores cristão mais próximos de Basílio, por exemplo, Gregório Nazianzeno, Anfilóquio de Icônio e Teodoreto de Ciro. Parece, contudo - como veremos mais abaixo -, ser peculiar a Basílio a observação segundo a qual as abelhas não pousam indistintamente sobre todas as flores. Efetivamente, segundo esta metáfora que Basílio, ao ampliá-la, introduziu no seu método fundamental de educação, as abelhas, à diferença dos outros insetos - que se limitam "ao gozo do perfume e da cor das flores" - sabem delas extrair também o mel. Similarmente, diz o autor, aqueles que na literatura e na filosofia "procuram não somente deleite e prazer", mas buscam igualmente delas retirar benefícios para o espírito, estes só tendem a progredir no conhecimento das sagradas doutrinas e na obtenção de sua salvação. Convém, todavia, notar que Basílio não desdenha, pura e simplesmente, o deleito e o prazer que possam redundar dessas leituras; o que ele diz é: “não somente deleite e prazer". Significativo também é o fato de ele agora empregar o verbo na primeira pessoa do plural, quando admoesta: "Devemos, pois, utilizar aqueles livros seguindo em tudo o exemplo das abelhas". ${ }^{24}$ É que as abelhas, observa Basílio, não pousam indistintamente sobre qualquer flor, nem procuram também delas tudo carregar e de tudo usufruir. Ao invés, elas colhem somente o pólen que é necessário para a produção do mel, deixando para trás tudo aquilo que é supérfluo. Do mesmo modo, pondera o teólogo, "caso sejamos sábios", tomaremos de empréstimo aos escritos dos pagãos somente aquilo que for conforme à verdade, deixando para trás o que não convém. Mas Basílio não se contenta em empregar somente a metáfora das abelhas, ele se serve também de outras imagens que vêm, por assim dizer, ilustrar e embelezar ainda mais esta tradicional metáfora. Com efeito, ajunta o autor: "E como, colocando-nos

\footnotetext{
${ }^{23}$ Ibid., IV, 2.

${ }^{24}$ Ibid., IV, 9.
} 
a colher das flores da roseira, evitamos os espinhos, assim também, colhendo dos livros dos pagãos tudo o que for útil, devemos precaver-nos daquilo que é nocivo". ${ }^{25}$

Ora, se comprarmos as considerações aduzidas no Capítulo IV do Discurso com o que mais acima lemos na Carta 223, 2, onde Basílio confessa: "percebi a inutilidade da sabedoria dos príncipes deste mundo", é lícito concluir que a sua escrita e o seu pensamento revelam também afirmações de caráter paradoxal. E isto é tanto mais patente quando se pensa na metáfora das abelhas, que eu acabei de brevemente analisar. Se também considerarmos o início do Capítulo V do mesmo Discurso, veremos que, ao introduzir o tema da virtude, o teólogo afirma sem rodeios: "Ao elogio da virtude dedicaram muitos escritos os poetas, os prosadores e, ainda mais, os filósofos; para tais escritos devemos, sobretudo, voltar a nossa atenção". ${ }^{26} \mathrm{O}$ mais curioso é que, após recomendar a leitura daqueles escritos, Basílio manifesta o desejo de ver nascer na alma dos jovens uma certa familiaridade e um certo hábito na prática da virtude, pois, ajunta ele: "Justamente tais ensinamentos permanecem indeléveis por natureza, imprimindo-se profundamente no espírito sensível dos jovens". ${ }^{27}$ Mais surpreendente ainda é vê-lo evocar a autoridade do próprio Hesíodo, ao reconhecer que o seu escopo, ao compor os seus versos, não foi outro senão o de exortar os jovens à prática da virtude. Aqui Basílio cita diretamente uma passagem da obra Os trabalhos e os dias: "Escabrosa e impraticável, plena de tantos suores e fadigas, alcantilada, é no início a estrada que conduz à virtude". ${ }^{28}$ Em seguida, o autor do Discurso parafraseia o poeta ao ponderar que nem todos são aptos a subir por esta estrada, dada a sua escabrosidade e, portanto, a dificuldade de se chegar agilmente ao seu ápice. Todavia, quem conseguir atingi-lo poderá contemplar do alto o quanto esta estrada é plana e bela, melhor ainda, ela é fácil e praticável e muito mais agradável do que aquela outra que conduz ao vício. Esta é a razão pela qual o teólogo volta a enaltecer as palavras do poeta, ao afirmar: "Por isto, parece-me que Hesíodo tenha assim escrito unicamente para exortar-nos à virtude e para estimular-nos todos à pratica do bem e para que, desencorajados diante das provações, não devamos renunciar à meta". ${ }^{29}$

\footnotetext{
${ }^{25}$ Ibid., IV, 10. Itálicos meus.

${ }^{26}$ Ibid., V, 1. Itálicos meus.

${ }^{27}$ Ibid., V, 2.

${ }^{28}$ Ibid., V, 3. Com relação à citação de Hesíodo, veja: HESÍODO. Le opere e i giorni, Parte Prima, 295. Milano: BUR, 2006.

${ }^{29}$ Basilio di Cesarea. Discorso ai giovani, op. cit., V, 5.
} 
Mas não é somente Hesíodo que Basílio considera um paladino da virtude. Nesta mesma ordem ele coloca também as figuras de Homero, Teógnis, Sólon e, curiosamente, a do sofista Pródico de Ceos. Sobre este último ele pondera: "Também para ele deve voltar-se a nossa atenção, porque é um homem que não se deve desprezar" ${ }^{30}$ Não contente com estes nomes, o autor prossegue, no Capítulo VII, referindo-se aos exemplos de Péricles, de Euclides, de Alexandre Magno e, como era de se esperar, do próprio Sócrates. Com relação a Sócrates, ele chega mesmo a exaltá-lo como exemplo de humildade que, de certa maneira, preludia o que está escrito no Evangelho de Mateus: "Eu, porém, vos digo: não resistais ao homem mau; antes, àquele que te fere na face direita oferece-lhe também a esquerda" (Mt 5, 39). ${ }^{31}$ Note-se, porém, que Basílio não faz uma menção explícita ao texto de Mateus, mas ele alude àquela passagem com estas palavras: "Porque a atitude de Sócrates (de não resistir a um maltrato) responde àquele preceito que exorta a oferecer também a outra face a quem nos bate, ao invés de opor-lhe resistência". ${ }^{32}$ Além de Sócrates, o teólogo menciona as figuras de Péricles e Euclides como exemplos daqueles grandes homens que souberam fomentar a busca do conhecimento e a prática das virtudes.

\section{Conclusão}

Conquanto eu me tenha centrado na obra, Discurso aos jovens, pode-se fazer uma ideia de que Basílio também não está isento dos paradoxos e das ambiguidades que todo texto - dada a própria dinâmica e a experiência da escrita - encerra. Neste sentido, é bem verdade que ele coloca - e não poderia de outra maneira - a doutrina, a sabedoria e a cultura cristãs numa ordem de superioridade com relação à cultura e ao pensamento pagão. Todavia, como vimos ao longo destas reflexões, ele não hesita em recomendar que se recorra a esta mesma cultura pagã para que dela se extraia o que ela tem de melhor. Ao contrário de Tertuliano, Basílio não vê um abismo intransponível entre fé e razão, ou entre "sabedoria cristã" e "sabedoria pagã", mas, antes, uma ponte, um caminho ou um vínculo ligando estes dois domínios do saber. Convém, todavia, lembrar que Tertuliano, por mais que afirme - e de maneira categórica - que a fé prescinde da filosofia, ou deve prescindir da filosofia, ele está constantemente a fazer referência a esta mesma filosofia que ele

\footnotetext{
${ }^{30}$ Ibid., V, 13.

${ }^{31}$ Cf. ibid., VII, 8.

${ }^{32}$ Ibid.
} 
despreza, ou pretende desprezar. Mas Basílio tampouco equipara a cultura cristã à cultura pagã, no sentido em que ambas reproduziriam ipsis litteris a mesma verdade. Ele se coloca antes, conforme eu acentuei ao longo deste estudo, naquela via mediana que, na terminologia de Rogério Miranda de Almeida, se situa num entre-dois, vale dizer, numa dinâmica de exclusão e inclusão, de valoração e revaloração, de interpretação e reinterpretação. É o que o autor de Nietzsche e o paradoxo designa pela expressão: "o paradoxo de uma exclusão interna". Isto quer dizer que Basílio, ao sublinhar a superioridade da cultura cristã, da revelação contida nas Escrituras, da plenitude do conhecimento e da salvação operada por Cristo, está se excluindo do pano de fundo no qual ele se formou (a cultura grega) e ao mesmo tempo dele fazendo parte, porquanto ele continua recorrendo a esta mesma cultura para ampliar, aprofundar e explicitar ainda mais aquilo que se encontra na sabedoria cristã. Em contrapartida, por mais que ele acentue a riqueza contida na literatura e na filosofia gregas, ele admoesta seus pupilos a não abraçarem indiscriminadamente ou a não adotarem a primeira ideia que depararem no abundante tesouro desta cultura pagã.

Tomemos, por exemplo, a questão das virtudes e repitamos: por mais que Basílio enalteça o exemplo dos pagãos quanto à prática da prudência e da coragem, somente as Escrituras serão aptas, segundo ele, a nos conduzir àquela vida futura que corresponde à salvação. De um lado, portanto, a ética basiliana se apresenta como uma ética baseada no conhecimento transmitido pela revelação e, consequentemente, como uma ética da intencionalidade, pois ela visa um fim, que é a vida futura. De outro lado, porém, convém enfatizar que, embora o teólogo coloque a "vida futura" numa ordem superior à desta vida terrena, ele não o faz à maneira de um Taciano ou de um Tertuliano que, peremptoriamente, excluem toda ingerência da razão, todo raciocínio baseado na dialética e, enfim, todo apelo à filosofia e à cultura pagã como coadjuvantes no caminho da salvação. Na verdade, tanto Basílio Magno quanto os outros dois Padres Capadócios seu irmão, Gregório de Nissa e seu amigo, Gregório Nazianzeno - privilegiam aquela via intermediária que aponta paradoxalmente para uma tendência de complementariedade ou, em outras palavras, de um entre-dois, de um meio termo, de uma medianidade ou de uma passagem entre estas duas esferas da sabedoria: a sabedoria pagã, ou profana, e a sabedoria cristã ou, na linha do Apóstolo Paulo, a "sabedoria do mundo" e a "loucura da cruz". 


\section{Referências}

ALMEIDA, Rogério Miranda de. Agostinho de Hipona e as ambivalências do seu filosofar. In Revista Veritas, v. 57, n. 2, maio/agosto 2012.

. "Filosofia cristã": Reflexões em torno de uma polêmica. In Espiritualidade, saúde e cultura: A teologia nas fronteiras. Curitiba: Juruá, 2016.

BASÍLIO DE CESAREIA. Discorso ai giovani. Bologna: EDB, 1998.

. Letters, vol. II (186-368). In The Fathers of the Church. Washington, D.C.:

The Catholic University Press, 2008.

Bíblia (A) de Jerusalém. São Paulo: Paulus, 1995.

FEDWICK, Paul Jonathan (ed.). Basil of Caesarea: Christian, Humanist, Ascetic. A sixteen-Hundredth Anniversary Symposium. Toronto: Pontifical Institute of Mediaeval Studies, 1981.

HESÍODO. Le opere e i giorni. Milano: BUR, 2006.

JACKS Leo V. St. Basil and Greek Literature. Washington D.C.: Catholic University of America, 1922.

JUSTINO DE ROMA. I e II Apologias; Diálogo com Trifão. São Paulo: Paulus, 1995.

KUSTAS, GEORGE L. Saint Basil and the Rhetorical Tradition. In Basil of Caesarea: Christian, Humanist, Ascetic. A sixteen-Hundredth Anniversary Symposium. Paul Jonathan Fedwick (editor). Toronto: Pontifical Institute of Mediaeval Studies, 1981.

PLATÃO. Republic. Cambridge/London: Harvard University Press, 1978.

RIST John M. Basil's “Neoplatonism”. Its Background and Nature. In Basil of Caesarea: Christian, Humanist, Ascetic. A sixteen-Hundredth Anniversary Symposium. Paul Jonathan Fedwick (editor). Toronto: Pontifical Institute of Mediaeval Studies, 1981.

TERTULIANO. Contro gli eretici. Roma: Città Nuova, 2002. 